\title{
Post-transition period and quality of higher education: ways to overcome the crisis phenomena
}

\author{
K. I. Suleimenova ${ }^{1, *}$, P. V. Obukhova ${ }^{2, * *}$, D. B. Shaltykova ${ }^{3, * * *}$, \\ I. E. Suleimenov ${ }^{3, * * * *}$ \\ ${ }^{1}$ Birmingham University, Edgbaston, Birmingham, B15 2TT, United Kingdom \\ 2Satpayev Kazakh National Technical University, 22 Satpayev av. Almaty, Kazakhstan \\ ${ }^{3}$ Almaty University of Power Engineering and Telecommunications, 126 Baitursynova Str., \\ Almaty, Kazakstan

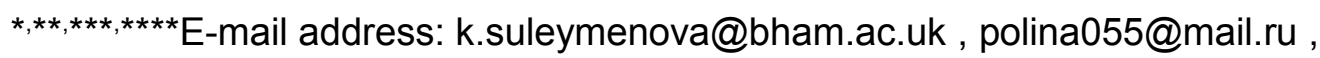 \\ dina_65@mail.ru , esenych@yandex.ru
}

\begin{abstract}
The evidence of appearance of post-transitional crises previously predicted by methods institutional economy is given on the base of data obtained by interview method. It is shown that decreasing of quality of engineering education in Kazakhstan may be considered namely as posttransition phenomenon, which is determined mostly by the inertia of mass consciousness that was formed during the period of transition from the plan economics to the market one rather than financial factors. Some possibilities of overcoming of observed negative trends are discussed.
\end{abstract}

Keywords: post-transitional crisis; institutional economics; quality of education; innovation cluster

\section{INTRODUCTION}

Economics of a period of transition from the plan economics to the market one (hereinafter referred to as the economics of the transition period) is described with several specific features considered in detail in [1-5]. Some of the contradictions of the transition period are overcoming in a form of crises of different kinds, which nature was studied in [2-5], as it was dramatically demonstrated in the post-Soviet countries.

Further studies in this direction showed [6] that not only transition period leads to quite definite crises; one can predict crises of the post-transition nature too. The forecast of the posttransition crisis was carried out in the quoted work [6] by methods of the institutional economics, in particular, it was noted that the specified crises can appear in the different spheres of social life.

A forecast provided in [6] can be considered to be proved true, at least, in respect to economic factors having direct impact on the quality of for the Mater Students education, as it is shown in this work, based on the observations made concerning the situation in the Republic of Kazakhstan. It is showed that increase of living standards and incomes of Kazakhstan people in the recent few years (according to classification [6], this period belongs to the post-transition one) has negative impact on the quality of higher education. On some parameters, the level of 
the specified negative impact even exceeds the negative impact on the level of engineer education caused by the decrease of living standards during the beginning of the transition period.

Within this work, the measures are discussed to overcome the specified above negative trends. It is showed the key factors include international cooperation and generation of the educational/scientific innovative clusters able to serve as the business-incubators for the startup companies forming by young scientists.

\section{SOURCE OF DATA}

Conclusions were made taking into account results of the anonymous private interviews of two types carried out among the Master Students of technical departments of several universities of Almaty and correspondent alumni. Anonymous and private nature of the interviews was aimed to reflect the negative features of the higher education in the Republic of Kazakhstan; besides, answers for some questions included confidential information. Within the first interview, respondents were asked to answer the following questions:

- Do you have a permanent job not connected with education for the Master Degree?

- Are you involved in some activity generating income not connected with your education or permanent job?

- Specify your average monthly salary at your permanent job, if any.

- Specify duration of your working hours a week at the permanent job.

- Specify the number of hours allocated for classes on your specialty a week.

- Specify the time that you actually spend to attend your classes and execution of independent work.

37 Master Students of three technical universites of Almaty took part in this interview. The second interview was of retrospective nature, and alumni of technical universities also took part in it. The following questions were asked:

- Have you had a permanent job not connected with your education for the Master Degree within the period of education?

- Evaluate your average monthly salary at your permanent job within the period of education for the Master Degree.

Thus, the second interview was directed for obtaining the same data but it was designed for the retrospective analysis and it was carried out in the reduced variant.

\section{RESULTS}

A diagram of employment of the Master students at jobs not connected with education is presented on Fig. 1. The diagram shows that the majority of the interviewed students have a permanent job, and it is interesting to note that the percentage of students, which have a permanent job and additional sources of income not connected with education in the university, is comparable with the total number of the partially employed students.

Diagram of the relative share of time spent for education and job not connected with education is presented on Fig. 2a; Fig. 2a is constructed based on the formal and verified data; Fig. $2 b$ is constructed based on the own subjective assessments made by the Master students. It 
is shown that the relative share of time spent directly for education is very small. Discrepancies of data of Fig. 2a and Fig. 2b cannot be considered as significant on such background. Dynamics of growth of income of the employed Master students and average annual data obtained on the basis of the retrospective interview of the alumni is presented at Fig. 3.

\section{$1 \square 2 \square 3 \square 4$}

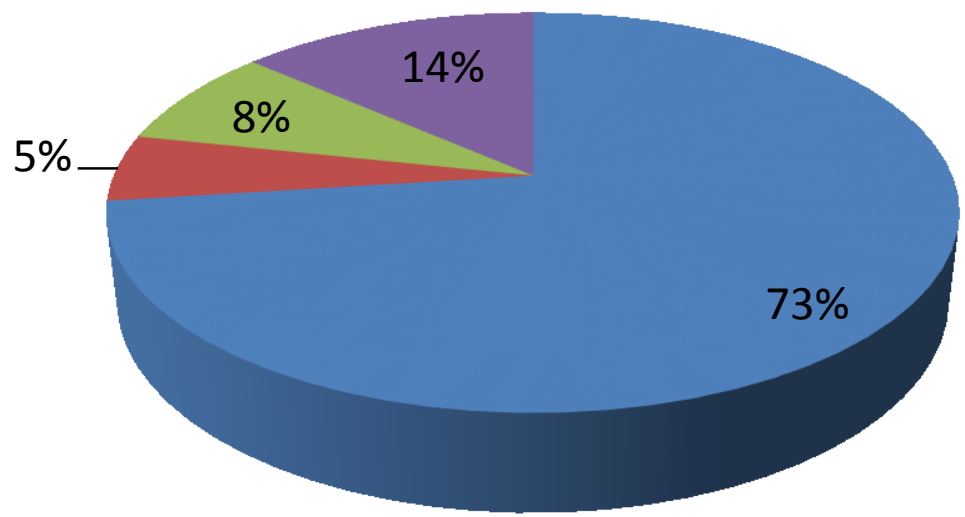

Figure 1. Diagram of employment of the Master students of the Almaty universities at the jobs not connected with education. 1 - students employed at the permanent job, 2 - employed at the permanent job and having some additional source of income, 3 - having some additional source of income, 4 not employed at the permanent job and not having any additional source of income.

$1 \square 2$

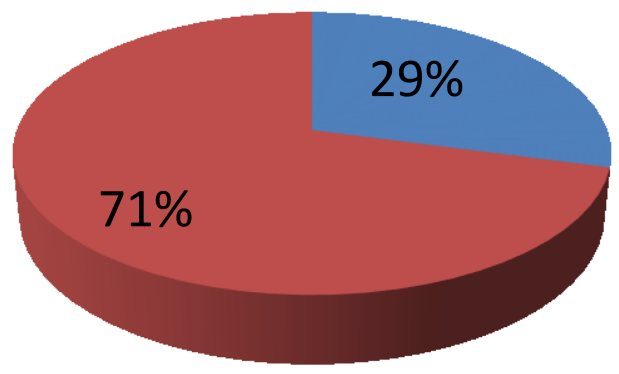

$1 \square 2$

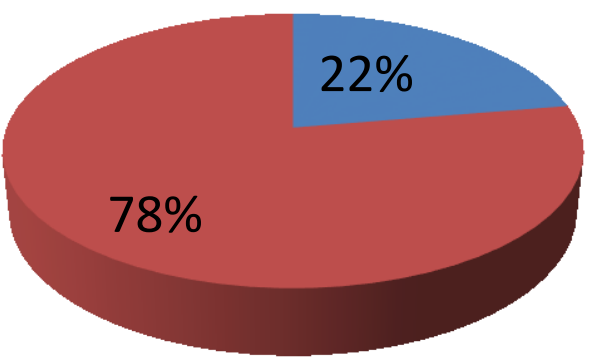

Figure 2. Diagrams of the relative shares of time spent by the Almaty Master students for education

(1) and job not connected with education (2); $2 \mathrm{a}$ - data on formal count of the working and educational hours, $2 \mathrm{~b}-$ own assessments of the interviewed students.

\section{DISCUSSION}

The data obtained showed a phenomenon which is absolutely not typical for the countries where a transition period did not occur or it was comparatively quick and painless (East Europe 
contries). In particular, it shows that education for the Master Degree is considered by the students themselves as something economically secondary as compared to the main job.

This data unambiguously indicate that main part of students in the Republic of Kazakhstan appreciates not knowledge itself but the corresponding formal certificates (diploma, etc.). This conclusion is confirmed by the data of Fig. 3: the level of income of the interviewed working students significantly exceeds an average per capita income in the Republic of Kazakhstan (51.4 thousand tenge for January 2013, in Almaty this indicator is higher in $2.3-1.6$ times $^{1}$ ), i.e. a permanent job cannot be considered as some necessary measure to meet the minimal needs within a period of education. If the job plays such role, there will be a transition to the partial employment.

Income, thousand tenge / month.

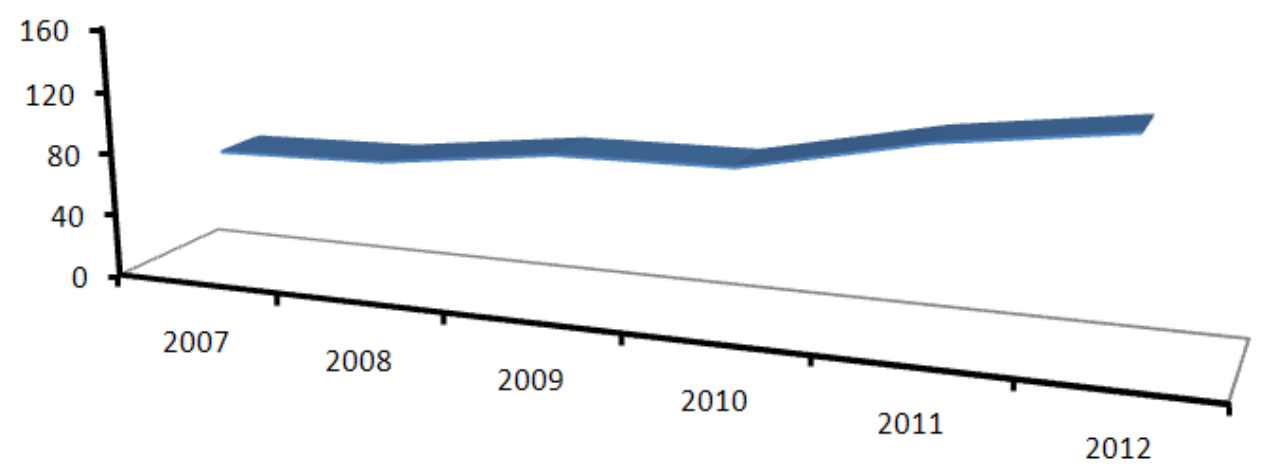

Figure 3. Diagram of growth of income of the Master students of the technical universities in the Republic of Kazakhstan employed at the jobs not connected with education.

It is not necessary to prove that absence of any motivation to obtain the knowledge itself (but not the formal certificates) results in decrease of quality of education; to confirm decrease of quality, it is enough to look at the data presented on Figure 2 - the students actually do not have any opportunity to get any technical education complying with the modern requirements.

A situation in the Republic of Kazakhstan is determined by several factors and the most of them are connected with inertance of the mass consciousness. It should be noted that the stereotypes of mass consciousness determining behavior of the students were formed namely in the transition period. (Transition period was started in the Republic of Kazakhstan in 1992, i.e. personality of the modern students was developed during the transition period). This factor forces us to consider absence of any motivation for obtaining of knowledge (actual education) especially as a post-transition phenomenon ${ }^{2}$, because it is completely caused by the stereotypes formed during the transition period, which continue to exist due to inertia of the mass consciousness.

In particular, the following stereotypes, which reflect (in the distorted form) a social meaning of the higher education, were formed in the mass consciousness of the countries with a long period of transition from the plan economics to the market one showing.

\footnotetext{
${ }^{1}$ News - Kazakhstan dated 20.06.13, http://newskaz.ru/economy/20130313/4872076.html

${ }^{2} \mathrm{~A}$ term is used in the meaning [6]
} 
- Personal investment (in terms of the efforts and money spent) into the actual technical education is not justified; a career of the manager is the most effective.

- For the career of the manager, actual education and actual level of competence is not valuable, corruption instruments and family and clannish connections are dominant for the career.

- A personal status in the youth environment is completely defined by the level of income and the level of education does not have any value and influence.

The mentioned stereotypes of mass consciousness in the Republic of Kazakhstan have very deep roots and bring to nothing most of the initiatives directed to improvement of the situation, especially, if the last initiatives are connected with use of the instruments of administrative regulation. It is obvious that such instruments can have very small impact on the dominant factor in quality of higher education - personal motivation.

It should be noted that the above mentioned stereotypes are the myths (in this context, a "myth" is not a synonym of the "false"); they only partially reflect the reality. In particular, it is possible to provide some examples when the family and clannish connections provide a career of some people but at the same time a period of 2009-2013 is also represented by the significant changes in the financial status of the different social layers, which gives are very well opposite examples.

In particular, direct investment to the innovative activity significantly increased during the mentioned period in the Republic of Kazakhstan. From 2011 to 2012, the total scope of financing of the scientific researches increased from 20.2 to 46.6 billion tenge, i.e. in 2.3 times $^{3}$. As for one employee involved into the scientific activity, a level of financing of the scientific researches in the Republic of Kazakhstan is equal to $\$ 16600$; it can be compared with the similar indicator in the EU countries.

Correspondingly, a special stratum started to form during the specified period in the Republic of Kazakhstan consisting of people involved into the scientific and innovative activity which income significantly exceeds an average level, however, it does not provide a necessary level of innovative development for the state in whole (the fact may be considered as a posttransitional crisis too).

Another example is connected with generation of the 'gray' IT-sector where income also exceeds an average level. These examples enable us to state that stereotypes of mass consciousness do not completely reflect the reality but are predominantly determined by the inertial factors.

Therefore, the key factor in getting over the negative trends in the Republic of Kazakhstan at the modern stage is not only in the field of administrative regulation but also in the sphere of mass psychology and institutional economics. Significance of methods of the latter is in search of ways to form the formal and informal institutions able to transform images fixed in the mass consciousness.

Partly, such measures are realized in the Ministry of Education and Science of the Republic of Kazakhstan. For example, nowadays traineeship of the Master students in the leading foreign scientific and educational centers is obligatory. Some departments of the Almaty universities have already involve more $90 \%$ of students in such international programs. (Such programs are aimed to demonstrate advantages of real higher education including the preferences which a qualified professional can obtain in the modern world.)

\footnotetext{
${ }^{3}$ According to the report of the Minister of Education and Science of Kazakhstan at the plenary meeting of the Republican Forum of scientists, Almaty, April 12, 2013.
} 
However, such programs themselves cannot overcome the stereotypes mentioned above. It is necessary to provide the obvious evidence of efficiency of the personal investment in the higher education, and such evidence shall be weighty enough to "swing a pendulum contrariwise".

Creation of the youth startup companies with a high profitability is one of options to realize such an approach. Personal example of young engineers achieved a big success due to the own scientific ideas can significantly change the stereotypes in the youth environment.

Now such innovative scientific/educational clusters are created in the Republic of Kazakhstan under auspices of the National Engineering Academy of Science of the Republic of Kazakhstan. Such clusters are designed to solve the same tasks as the existing technical parks, business-incubators, etc., however, they are created on the different economic concept then the existing analogues. Further we will show that solution of the problem connected with motivation of participation in the scientific studies requires the significant revision of approaches to management and financing of scientific studies.

Let us show it. The main idea of such structures as investment funds and/or businessincubators can be formulated as follows. There is some inventive entity needed in support (financial, legal, administrative, etc.) to implement its project. Experts of the corresponding funds (technologic parks, business-incubators, etc.) can evaluate the prospects of such ideas and make a decision to provide the relevant support.

It is not necessary to prove that the same scheme of investment is used by any institutions providing financial grants for scientific studies, i.e. in modern conditions such a scheme is one of the main financial instruments of management of the scientific studies (at least, any other instruments of economic regulation of scientific R\&D are not actually used in the post-Soviet countries).

There is the following main disadvantage of the considered scheme. Stating the project objectives, any researching group considers its own scientific interests. In the other words, such group solves a certain problem and only then it tries to promote the corresponding results to the market. As usual, each researching group operates on rather narrow site of the total frontier of the scientific studies. On producing new results, the tasks are modified but the general direction stays unchanged and it is necessary to make more and more efforts to find a place in the market for the new inventions.

It is reasonable to believe that the opposite approach shall be much more efficient in the modern conditions. In this case, a scientific task solved by the researching group meets requirements of the market. Instead of the question "How we can promote our studies at the market?" it is necessary to ask another question - "What studies we have to provide to enter the market?"

In the modern conditions when a market is very dynamic, a marketing expert shall become the central person at planning of the scientific studies - i.e. a professional able to forecast the market requirements for the products not created yet. Unfortunately, such experts are not included into the most researching groups. Besides, it can be unlikely realized in practice, and such a specialist of the specified profile will certainly provide interests of a big number of groups due to the obvious factors connected with a scope of the performed works.

Therefore, implementation of the alternative approach assumes certain centralization at planning of scientific studies - though on the level of the individual marketing expert representing a connecting link for several researching groups. In terms of institutional economics, it means that there are all preconditions for transition from the financial management of the scientific studies to informational one. 
Indeed, the main factor of activity of any researching group is represented by the risk connected with an unclear opportunity to promote the final product to the market.

Coming back to the issue on motivation of young scientists to take part in scientific studies, one can say as follows. It is rather simple to create a startup company but the level of the above mentioned risk makes alumni of universities find their position at the already existing markets that significantly decreases the innovative component. Alumni of the universities prefer creating the web sites (already demanded product) thinking on the lower level of salary and will not create the high risk innovations - for example, a new electronic devices, etc.

Besides, the experience shows that certain groups will never the innovative and investment risk and, therefore, this risk will be always delegated to the Government interested in the system innovations.

The above mentioned existing scheme assumes that the state institutions will take this risk; and it is known that efficiency of the goverment investment in scientific studies is very low [7]. It is one more reason to search the alternative schemes.

An alternative approach where scientific activity is based on the market requirements can overcome the above specified hardships. In this case, the state (represented by the corresponding institutions) undertakes not financing of the studies but setting of the task and obligations on purchase of the finished scientific and technical products. It is important that the task shall be stated in details - up to specification of the technical features of the finished products, requirements to the designing solutions, etc. (Not detailed and general statements will turn the situation back to the existing scheme of the grant financing.)

There are obvious benefits for the state. For the first, financial risks are significantly decreased in this case because only the finished product is paid. For the second, there is an opportunity for real involvement of the young professionals in innovative activity because the tasks set by the market often do not require too high experience. For the third, such an approach provides significant increase of the communicative integrity of the scientific space. The existing scheme is directed to the already established and fixed groups while the supposed approach is not connected with interests of the certain groups and it will cause creation of the interdisciplinary groups (as usual, the modern requests of the market for the innovative products are of the interdisciplinary nature).

\section{CONCLUSION}

Thus, at the present time, in spite of the significant financial investment in the scientific studies, there is a very low level of involvement of the young professionals in the scientific studies in Kazakhstan. Besides, certain data show that there is also very low motivation of the Master students to obtain knowledge necessary for the professional work. Reasons of such negative phenomena are not connected with financial factors; they are mainly determined by the stereotypes of the mass consciousness and can be considered as a typical phenomenon of the post-transition nature.

To overcome such phenomena, it is not enough to use additional financial instruments; tools of informational regulation should become the most important. One of such methods can include creation of the innovative clusters of a new type which main objective will consist of setting the problems complying with the certain market requests and providing the real financial success of the youth startup companies, mainly, due to the information support. 


\section{References}

[1] Brezis Elise S., A. Schnytzer, "Why are the transition paths in China and Eastern Europe different? A political economy perspective", Economics of Transition, 11(1) (2003) 3-23, Ed. The European Bank for Reconstruction and Development, published by Blackwell Publishing.

[2] Frye T., A. Shleifer, "The Invisible Hand and the Grabbing Hand", The Transition from Socialism, 87(2) (2001) 354-358.

[3] Bazzoli, Laure, and Thierry Kirat, "A propos du réalisme en économie des institutions et ses implications sur l'analyse des fondements juridiques des transactions économiques: Commons versus Williamson." Economie Appliquée, 56(3) (2003) 171-209.

[4] Pomfret Richard, "Lessons from Economies in Transition from Central Planning", The Australian Economic Review, 36(2) (2003) 245-52, Ed. Blackwell Publishing Asia Pty Ltd.

[5] Berthomieu Claude, Anastasia Ri, Kamilya Suleymenova, Irina Syssoyeva (Masson), (2009) "Impacts of world economic crisis on financial sector stability and economic security of countries", Second Astana Economic Forum, (Astana, Kazakhstan), 11-12 Mars (2009).

[6] Suleymenova Kamilya, Institutions, efficacité économique et autoritarisme politique: cas de la Chine et de la Russie, Thèse de doctorat: Sciences économiques, Centre d'Etudes en Macroéconomie et Finance Internationale, Nice, (2012).

[7] Yergozhin Ye. Ye., Aryn Ye. M., Suleimenov I. E., Mun G. A., Belenko N. M., Gabrielyan O. A., Park N. T., Negim El-S. M. El-Ash., Suleymenova K. I., Nanotechnology versus the global crisis / Hollym Corporation Publishers, Seoul, (2010), 300. 